Original Research Paper

\title{
Towards the Efficiency of Municipal Solid Waste Management in the Democratic Republic of Congo (DRC): Case Study of Lubumbashi
}

\author{
${ }_{1,3,4}$ Martin T. Mpinda, ${ }^{2}$ Olusegun K. Abass, ${ }^{1}$ Mujinya B. Bazirake, ${ }^{3}$ Eric M.M. Nsokimieno, \\ ${ }^{4}$ Ngoy S. Mylor, ${ }^{4}$ Kayembe W.M. Kayembe, ${ }^{3}$ Sissou Zakari and ${ }^{5}$ Rodrigue Khonde \\ ${ }^{I}$ Biogeochemistry, Geology of Soil and Tropical Ecosystems Unit of Research, BESET, \\ Faculty of Agricultural Sciences, University of Lubumbashi, Lubumbashi B.P: 1825, DR. Congo \\ ${ }^{2}$ Institute of Urban Environment, Chinese Academy of Sciences, Xiamen, 361021, P.R. China \\ ${ }^{3}$ School of Environmental Studies, China University of Geosciences, Wuhan, Hubei 340074, P.R. China \\ ${ }^{4}$ Department of Natural and Renewables Resources Management, \\ Faculty of Agricultural Sciences, University of Lubumbashi, Congo \\ ${ }^{5}$ Department of Occupational and Environmental Health of the School of Public Health, \\ Huazhong University of Science and Technology, Wuhan, Hubei, 430030, P.R. China
}

Article history

Received: 04-02-2016

Revised: 22-05-2016

Accepted: 27-05-2016

Corresponding Author:

Martin T. Mpinda

Biogeochemistry, geology of

Soil and Tropical Ecosystems

Unit of Research, BESET,

Faculty of Agricultural

Sciences, University of

Lubumbashi, Lubumbashi B.P:

1825, DR. Congo

Tel: +2430978209494

Email: mtmartin925@gmail.com

Olusegun K. Abass

Institute of Urban Environment,

Chinese Academy of Sciences,

Xiamen, 361021, P.R. China

Email: segunabass@iue.ac.cn
Abstract: This paper provides an overview on the state of Municipal Solid Waste Management (MSWM) in Lubumbashi, D.R Congo. To meet the recently proposed Sustainable Development Goals (SDGs), establishment of efficient waste management techniques and strategies geared towards monetizing waste in the framework of sustainable growth is inevitable. Solid waste categorization and collection in conjunction with recycle, reuse and revalue are efficient approaches that can be employed to overcome waste management problems affecting development in the neighborhoods and districts of Lubumbashi. Findings from this work reveal that there are no distinction between waste categories, especially the biodegradable waste fraction of various municipalities $(p>0.05)$ and other types waste examined in the study. However, significant fraction of construction waste was observed within dissimilar municipalities $(p<0.05)$. This notwithstanding, the municipality of Lubumbashi generates more waste fractions $(212 \%)$ than Katuba (114.20\%), Kamalondo (58.25\%) and Kenya (52.21\%). Notably, Kampemba municipality produce more composite waste $(54.5 \%)$ than others municipalities $(p<0.05)$. The lowest amount of composite waste comes from Kamalondo Township with 20.4\% proportion. Within the hazardous waste category, different toxic waste levels were found in four major municipalities $(\mathrm{p}<0.05)$. Overall, Kamalondo municipality waste is adjudged poorly managed with high amount of non-retrieved waste than other municipalities $(p<0.05)$ though, the amount of hazardous waste generated in Lubumbashi $(71.47 \%)$ is higher than other solid waste category observed. From the data set obtained, a conceptual model was developed to effectively manage the solid waste generated in Lubumbashi city.

Keywords: Solid Waste Management, Collection System, Lubumbashi, Solid Waste Distribution and Characteristics, Conceptual Model

\section{Introduction}

Solid Waste Management (SWM) encompasses several steps: Collection, transfer, resource recovery, recycling and treatment. Their applicability requires a sustainable SWM system that must be fully embraced by local waste management authorities in partnership with both public and private sectors. According to the 
USAID and World Bank, municipalities of developing countries usually spend 20 to $50 \%$ of their available municipal budget on SWM, which affords only less than $50 \%$ of the population (Henry et al., 2006; Memon, 2010). Population explosion, urban activities, infrastructure and resourcing problems, bureaucratic confusion, weakness of public power and poverty level are factors contributing to the abundance of illegal waste (domestic, industrial, manufacturing, medical, agricultural and sewage sludge) dump sites across developing cities of developing nations (Oteng-Ababio et al., 2013). This improper waste management system remains the same in most African cities. For instance, in Accra, Ghana, only $11 \%$ of the 1.4 million residents reportedly benefited from home waste collection system, while the remaining $89 \%$ dispose their waste at community dumps, in open spaces, water bodies and in storm drainages (Owusu Boadi and Kuitunen, 2002). Moreover, authorities in Tanzania collected an average $24 \%$ of disposed products (Kassim and Ali, 2006).

More than fifty years after independence, cities in Democratic Republic of Congo (DRC) still battles issues relating to high level environmental degradation and institutional dysfunctionalities. The production of urban waste is quite high at about 5,000 tons per day in Kinshasa in which $68 \%$ are biodegradable waste, $20 \%$ plastic, $10 \%$ metallic and the remaining $2 \%$ are others kinds of waste. The rapid urbanization rate has a visible effect on the accumulation of solid waste and environment degeneration, forming indicators of sanitation quality in affected cities as observed in Lubumbashi, the second largest city of DRC (Cobbinah et al., 2015). In addition, the inabilities of municipalities to neither analyze nor improve their waste management performance due to lack of education and environmental awareness within local municipality, poor financing of SWM by government parastatals and in some cases, unclear service pricing principles which are at variance with the law, have led to weak control of service quality.

Waste collection methods vary within countries and from one region to another, with less developed/developing countries lacking structured systems for salvaging waste. Traditionally, waste collection involves a connection between generating agents and managing agents. Therefore, to achieve specific waste collection goals, it is crucial to take into account the system users attitudes during the decisionmaking process (Bernad-Beltran et al., 2014). These considerations have motivated the need of unquestionable and adequate SWM scheme that is well acknowledged by various municipalities in developing countries (Guerrero et al., 2013).
Considering the foregoing, DRC cities solid waste management requires an innovative approach to changing their image and identity (Nsokimieno Eric et al., 2014). Furthermore, it is important to assess cityspecific waste management habits and willingness to participate in the implementation of new and strategic collection system. Thus, this work investigates the recent waste disposal pattern in Lubumbashi. It starts out with generation/disposal of waste and provides an adaptive framework for the Lubumbashi's waste management system in terms of waste generation and separation, collection, transfer and transport, treatment, recycling and final disposal. Further, we examined the relationship between the population rates and solid waste produced in the various municipalities. As there is not enough statistical information about the SWM schemes for many cities in DRC, most of the data analyzed in this study reflect the actual state of solid waste management in Lubumbashi.

\section{Materials and Methods}

\section{Study Area}

This study was conducted in the city of Lubumbashi (Upper Katanga, D. R. Congo) located between coordinates (11 ${ }^{\circ} 37^{\prime} 437^{\prime \prime}-11^{\circ} 42^{\prime} 52.9^{\prime \prime}$ and $27^{\circ} 27^{\prime}$ $48.9^{\prime \prime}-27^{\circ} 32^{\prime}$ 60.6') as shown in Fig. 1. GPS coordinates of all Municipal Solid Waste (MSW) were recorded in the field within each predetermined plot (Garmin $60 \mathrm{CSx}$, accuracy $\sim 5 \mathrm{~m}$ ) and compared with those of municipalities previously identified on the satellite images. Lubumbashi is an urban agglomeration with a population of about 1.5 million people (Brinkhoff, 2010). It is a flat city at an altitude of about 1200 m, drained by the Kafubu River and its tributaries and has a humid subtropical wet and dry climate (Kottek et al., 2006). The city is easily accessible by air, rail and highway. These transportation networks give the city a wide variety of quick access to its mineral resource and create room for economic development. Recently, flooding occurred in some of the districts of Lubumbashi and caused severe damage to live and properties but floodrelated gully found in this area is not as severe as that in Kinshasa (Arkamose, 2004). During the Second Congo War that started in 1998 and ended 2003, DRC was severely impacted and an armed conflict continues in parts of the country. Thus, a large proportion of the population lives in low-income settlements, including very poor informal settlements. However, the increasing surge of industries involved in copper smelting, textiles and food processing have led to urban economic growth and environmental degradation. 


\section{Spatial Distribution of Municipalities and Solid Waste Generation}

Lubumbashi is divided into 7 municipalities according to administrative functions including: Annexe, Kamalondo, Kampemba, Katuba, Kenya, Lubumbashi and Rwashi (Fig. 1). The city setting is segmented into modern city (down town inherited from colonization), official city (middle class cities structured by the natives) and parallel town (poorly developed zones). Slag production from installed plants in the modern zone is minimal and contains existing structures for waste collection but this system is poorly managed. The Official city level comprises four of the municipalities (Kamalondo, Katuba, Kenya and Rwashi) with excessive population growth compared to available infrastructure and facilities. Overcrowding is thus the source of the MSW generated in large numbers on streets, drainages and several unmanned sites and markets. Waste categories including house-wares, industrial, manufacturing, agricultural and sewage sludge are dominant in these zones. Part of the neighborhoods lacking amenities for waste management is the parallel town. This town inevitably transforms into zones with the highest municipal solid waste generation. Currently this heterogeneities are found almost in every plots of the country (Kubanza and Simatele, 2015).

A planned expansion of the city of Lubumbashi from its current 43 to 95 districts for effective waste management planning is underway. To achieve this purpose, the Urban Renovation Office focuses on strategies including income redistribution system which is one of the keys to achieving the Sustainable Development Goals. However, on a more realistic front, efficient waste management are generally in their infancy in sub-Saharan Africa and only few agencies and urban managers have a clear understanding of how to transform global principles of sustainable development into achievable outcomes (Patel, 2009).

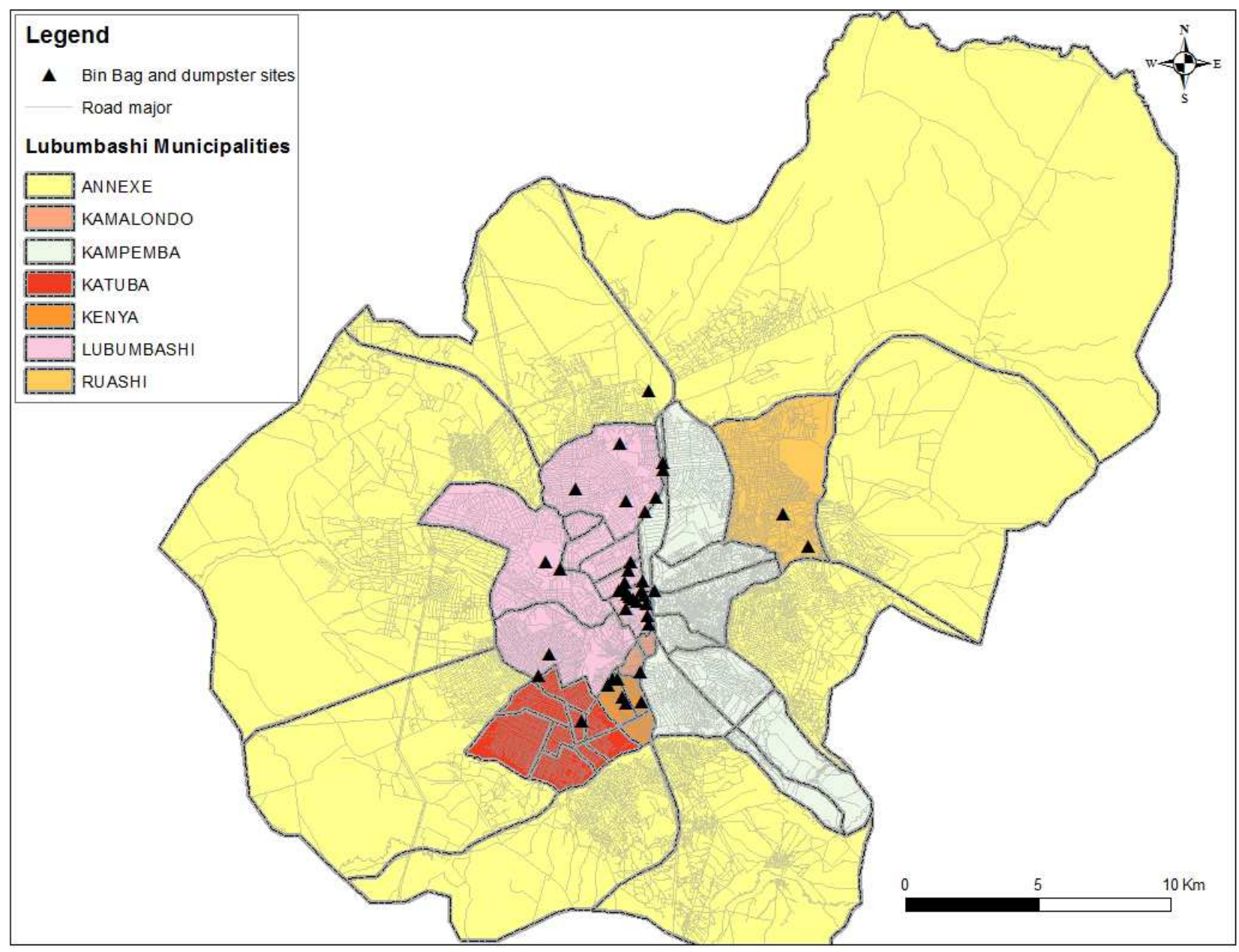

Fig. 1. Administrative map of Lubumbashi showing Bin Bag and Dumpster Locations (Source: This study) 


\section{Assessment Approach}

A desk study was conducted to assess background information on Municipal Solid Waste Management (MSWM) in Lubumbashi and data obtained was used for the construction of a conceptual model on MSWM in the city. Both primary and secondary data were collected from (6 municipalities of Lubumbashi city) respondents using questionnaires, interview and direct field sampling to obtain different opinions, reactions and ground evidence of factors contributing to the poor solid waste management in urban areas of Lubumbashi. The questionnaire contains 53 questions of which 5 are binary scale (Yes/No) questions while the rest are direct and general questions such as: How many trash bin do you have in all the municipalities; how many times do you collect solid waste in trash bin bag in each district; what is the prevailing waste collection system; how many tons do you collect in each trash bin bag each day; what lorry capacity are used for the solid waste collection; what nature of problem do you encounter during the collection and management of the solid wastes in each district and so on. These were used to update the data collected during the desk study.

The method adopted in this study provided interviewee with the opportunity of receiving clearer details on how to achieve an efficient waste management scheme and get clarification from the interviewer on issues affecting the disposal conditions and environmental fate of non-retrieved MSW. A $5 \mathrm{~m}$ square quadrant was used to assess the amount of solid waste in percentage according to their type and category. Documentary reviews were also conducted by reviewing regional environment management reports. The raw data obtained from the investigation were not normally distributed; hence, a non standard parametric test was used for the statistical analysis and processed using Spearman's correlation coefficient measures which helped to obtain relationships between municipality factors and waste categories. The values are at significant levels of $0.05>p>0.01$ (2-tailed). The information was subsequently analyzed using Statistical Package for Social Sciences (SPSS) Version 20.

\section{Results and Discussion}

\section{State of Solid Waste Collection System in Lubumbashi}

In remote areas of Lubumbashi city, waste incineration has been adopted by most householders as the most viable option and in their opinion could become easy to implement during dry seasons but almost impossible during the rainy season. Other residence improvised crude landfill system of digging and burying waste in the ground. Once filled, it is covered with earth and another is soon dug near the foremost. A third practice is to pay a street vendor who picks up the waste and dumps them in illegal areas. This is particularly harmful to nature and the environment because in the majority of cases, Congolese waste vendors dumps the collected waste into Rivers or in remote locations leaving no chance for authorities concerned to collect and properly dispose them. This practice is essentially common in most municipalities of Lubumbashi as shown in Fig. 2.

However, for city residence, waste containers are stationed in specific places (though not enough for the city coverage) where it could be used for waste deposal. Whereas, this idea is a step closer to a wider collection of waste, it is problematic because the containers are not regularly emptied and thus, overflowing on sidewalks and roads. The actual figures of waste collection bins on the streets of Lubumbashi city are shown in Table 1 and 2 (This figures however, does not represent the total waste generated, but collected in Lubumbashi). In total, the Avenues/Streets are equipped with a tray capacity of 8 tons, which make up a total of 18 containers installed in the city while in the rest of the municipalities, a total of 15 trays (with 33 containers) were installed.

The waste collection system is organized by the dispatch authorities in connivance with the Sanitation Department of Lubumbashi municipality. Ten Renault brand trucks with a capacity of 8 tons and three Trucks Benz (Tata) brand with a capacity of 20 tons each are employed for the collection, but only two are in full operation in the city. Besides, of the 100 waste collection bins available, only 33 are operational. Each truck makes five trips a day making a total of 40 tons at 8 tons per trip. This allows for a maximum collection of 120 tons of waste per day and an estimated 3,600 tons per month, invariably making a total of 43,200 tons collected annually. Waste collection is based on several factors including production capacity of waste in different places. Msiri (with about 24 tons waste per day) and Marche Mzee (with 40 tons waste per day) are the two major cities in Lubumbashi city having a very high production of waste due to economic activities in the community.

Raw household solid waste production in Lubumbashi municipality, amount to 51,840 tons annually. Other waste proportion generated annually in municipalities of Kenya, Katuba, Rwashi, Kamalondo and Kampemba are depicted in Table 2. The total solid waste production is estimated at 95,040 tons per year. However, this value is not a true reflection of the gross waste produced in Lubumbashi municipality, as some of the wastes are not collected because of the reasons already stated above. 

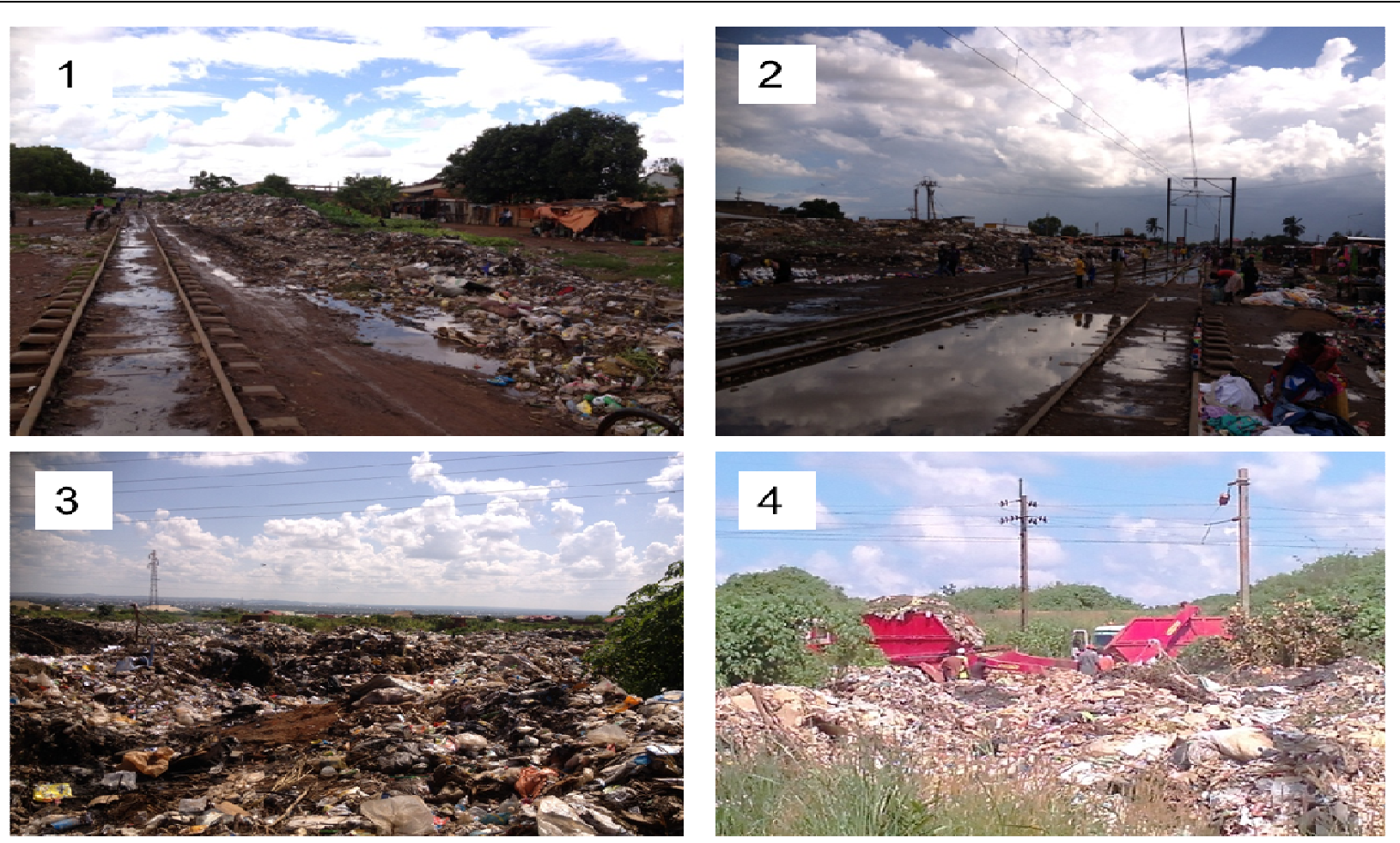

Fig. 2. Solid Waste Locations in: (1) Kenya Open Disposal; (2) Kamalondo Open Disposal; (3) Lubumbashi Local Municipality Final Disposal (Annex Municipality); (4) Lubumbashi Local Municipality Solid Waste Collection System

Table 1. Main locations of Lubumbashi local municipality solid waste collection

\begin{tabular}{llc}
\hline No. & Avenue & Collection bins \\
\hline 1 & Msiri & 3 \\
2 & Djamena & 1 \\
3 & Cadastre & 1 \\
4 & Tabora & 1 \\
5 & Tunnel & 1 \\
6 & Shalina & 1 \\
7 & Gare & 1 \\
8 & Marche Mzee & 5 \\
9 & Lomami & 1 \\
10 & Kapenda & 1 \\
11 & Obette & 1 \\
12 & Patrice Emery Lumumba & 1 \\
13 & ST Mazembe & 1 \\
& Total & 18 \\
\hline
\end{tabular}

Table 2. Dispatch waste collection bins in municipalities of Lubumbashi and production in tons per year

\begin{tabular}{|c|c|c|c|c|c|}
\hline Municipalities & $\begin{array}{l}\text { Number } \\
\text { (Dumpster) }\end{array}$ & $\begin{array}{l}\text { Quantity } \\
\text { (Tons) }\end{array}$ & $\begin{array}{l}\text { Day production } \\
\text { (Tons) }\end{array}$ & $\begin{array}{l}\text { Month production } \\
\text { (Tons) }\end{array}$ & $\begin{array}{l}\text { Year production } \\
\text { (Tons) }\end{array}$ \\
\hline Kenya & 8 & 8 & 64 & 1920 & 23040 \\
\hline Katuba & 3 & 8 & 24 & 720 & 8640 \\
\hline Ruashi & 2 & 8 & 16 & 480 & 5760 \\
\hline Lubumbashi & 18 & 8 & 144 & 4320 & 51840 \\
\hline Kamalondo & 1 & 8 & 8 & 240 & 2880 \\
\hline Kampemba & 1 & 8 & 8 & 240 & 2880 \\
\hline Annexe & 0 & 0 & 0 & 0 & 0 \\
\hline Total & 33 & 56 & 264 & 7920 & 95040 \\
\hline
\end{tabular}




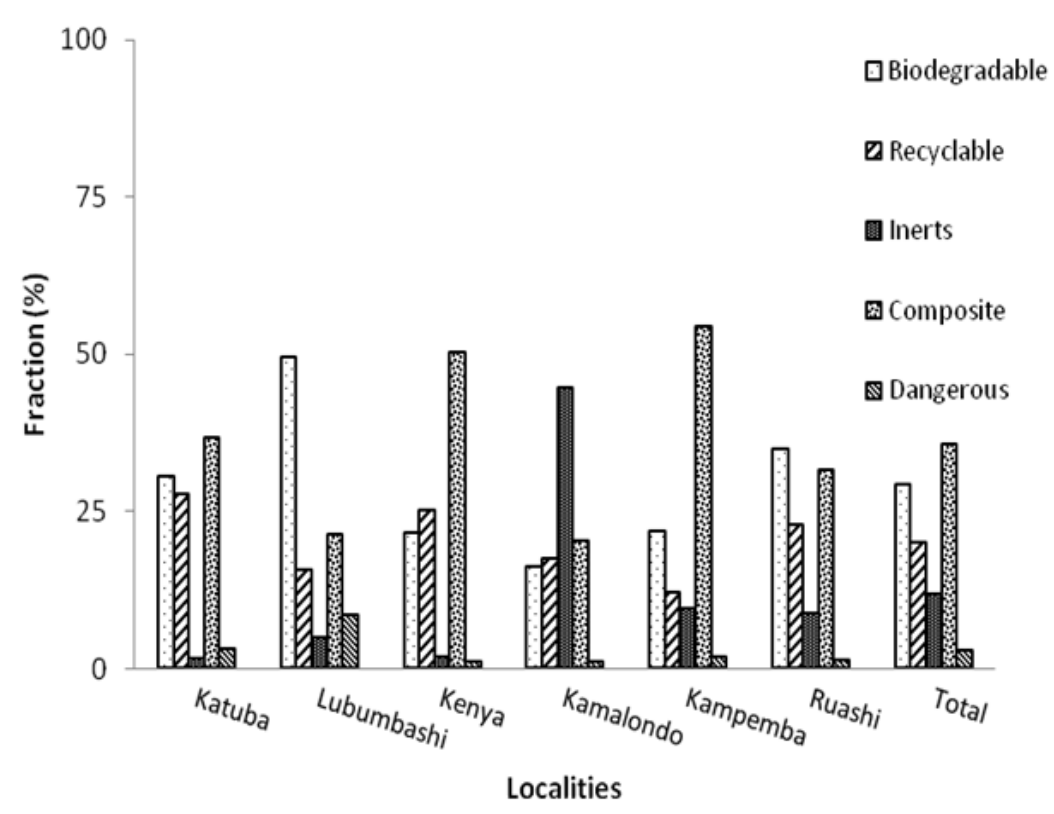

Fig. 3. Fractions by category of the total solid waste collected in Lubumbashi city

\section{Solid Waste Composition and Distribution Characteristics in Lubumbashi}

\section{Biodegradable Solid Waste Fractions}

The biodegradable solid waste (BSW) fractions in the various cities represent the amount of organic matter generated and disposed in landfills. The proportion of BSW in Lubumbashi is $29.2 \%$ of the total collected waste (Fig. 3). Within the municipalities, Lubumbashi municipality had $55.5 \%$ of the total BSW fraction generated, whereas Kamalondo had the least fraction of BSW (3\%). Following Lubumbashi is Katuba, Kenya and Ruashi with BSW fractions of 22.8, 8.1 and $6.5 \%$ respectively. BSW encompass two major problems: Its combination with chemical and microbiological material and its limited life time due to high moisture content and biodegradability. The solution to this problem requires segregation of the biodegradable fraction before waste collection, to reduce/prevent the contamination from hazardous components of municipal waste stream. In addition, drying of the BSW after separation from other waste to partially eliminate microorganisms present in the BSW can make it a viable end product for animals feeding (Garcia et al., 2005).

ANOVA test of the BSW within the various municipalities of Lubumbashi revealed no significant difference among the examined BSW categories $(p>0.05)$. The BSW was grouped in four categories (meals, green waste, paper and kitchen wasted) and the proportions of each category within municipalities is shown in Fig. 4. Green waste fraction, (39.5\%) was greater than the remaining BSW categories, followed by paper waste $(30.3 \%)$, kitchen waste $(22 \%)$ and meals $(8.2 \%)$ respectively. The highest fraction of paper waste was found in Lubumbashi municipality while Katuba and Kampemba have more green waste than the other municipalities apart from Lubumbashi. Ruashi BSW fraction was associated with the work life of indigenes who are civil servants of the state in the majority.

Lubumbashi had the highest green waste fraction within the BSW category. This is partially due to the community set-up and lifestyle. Lubumbashi municipality is composed of greeneries and the residences are mainly of the elite class. The BSW fraction was notably higher in Lubumbashi compared to other municipalities (Kamalando, Kampemba, Katuba, Kenya and Ruashi) because, Lubumbashi's BSW are collected in enclosed plots and the coordination effort is much higher than what is obtainable in the other districts where the BSW are discarded in plots without fence. The relatively large amount of green waste in Kampemba revealed the abundance of recycled organic waste (BSW) in the area. In other townships such as Kamalondo and Ruashi, the utilization and recycling of BSW was very low. Perhaps this limitation could be tied to lack of proper waste collection system resulting in the mixing of organic and inorganic fractions. Therefore, it would be incumbent on authorities concerned to give some economic support in order to make the recycling of waste fractions more competitive with other raw materials as feedstuff. 


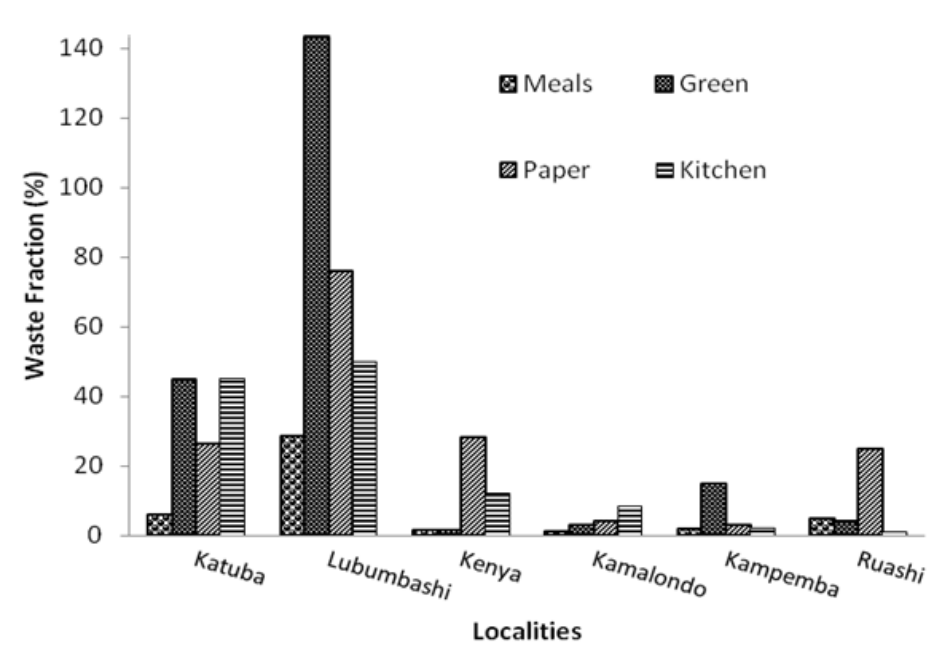

Fig. 4. Biodegradable solid waste fractions collected from seven municipalities in Lubumbashi

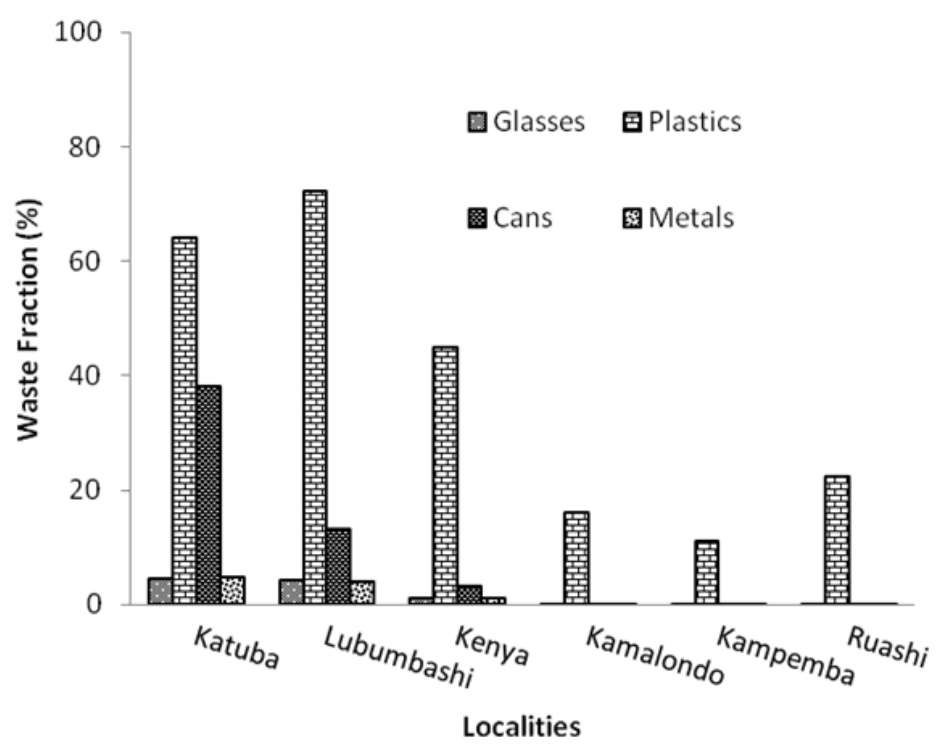

Fig. 5. Quantity of recyclable solid waste fractions from Lubumbashi city

\section{Recyclable Solid Waste Fractions}

The Recyclable Solid Waste (RSW) fractions in various municipalities represent the amount of RSW generated and disposed in landfills. The proportion of RSW in Lubumbashi municipalities represents $20 \%$ of the total collected waste (Fig. 3). Different fractions of RSW were found within the municipalities, $36.2 \%$ in Katuba, 30.4\% in Lubumbashi and $16.3 \%$ in Kenya. Kamalondo, Kampemba and Ruashi have RSW fractions of $5.7,3.9$ and $7.5 \%$ respectively. It is believed that miss-sorting at household level and impurities in source-separated RSW could lead to substantial losses during collection and process chain of recyclables (Cimpan et al., 2015). However, the nonparametric test showed no significant differences among
RSW fractions ( $>00.05)$ from the various municipalities. The RSW fractions are divided into four categories (glasses, plastics, cans and metals waste) and the proportions of each category within the city is shown in Fig. 5. Among the waste fractions of all the municipalities, plastics waste $(74.9 \%)$ was higher than other RSW fraction in the category, followed by cans $(18.1 \%)$, glasses (3.6\%) and metals (3.4\%), respectively. Lubumbashi, Katuba and Kenya municipalities had the highest content of plastics waste. Though, the dominant RSW fractions in all the municipalities are plastics waste, particularly in Ruashi, Kampemba and Kamalondo which contain more plastic waste than cans. Generally, Lubumbashi, Katuba and Kenya has the highest content of cans related garbage with the rate elevated enough than the rest of the townships following 
problems of high population density and weakness of the sanitation sector to manage waste generated in the community. Absence of trash bins equally contributed to the widespread of this fraction of solid waste. Hence, the weakness of the state environmental programs has been identified as a big factor limiting the descent management of this class of waste.

As shown in Fig. 5, more than $72 \%$ of waste fraction identified in Lubumbashi municipality, apart from Kamalondo, Kampemba, kenya, Lubumbashi, Ruashi and Katuba towns, ranks the municipality as the highest plastic waste mis-handlers in the city of Lubumbashi. This is closely related to the prevalent commercial activities undertaken by the township residence. Most townships use bottles and other types of plastics. Thus, high quantities of plastic garbage were also observed in townships such as Kenya, Katuba and so on. In addition, problems of population density, urbanization and lack of proper waste management sensitization contributed to the heightened levels of indiscriminate dumping of RSW in Lubumbashi city (DSCRP, 1999).

However, in developed countries like the EU, Waste Management Act has been disseminated proposing that by 2020 , recycling of waste materials such as paper from households should be increased to a minimum of $50 \%$ overall by weight (Põldnurk, 2015). Thus, separation of RSW is required in Lubumbashi city to efficiently manage this type of waste.

\section{Inert Solid Waste (ISW)}

The amount of Inert Solid Waste (ISW) in Lubumbashi municipalities represents $12 \%$ of the total collected waste (Fig. 3). A significant difference $(p<0.05)$ was observed among the various municipalities in relation to construction waste. Within the municipalities, various quantities of ISW were observed in Kamalondo (43.6\%), 28.7\% in Lubumbashi and $9.3 \%$ in Kampemba. Ruashi, Katuba and Kenya, have ISW fractions of 8.7, 6.2 and $3.6 \%$ respectively. Comparing the waste types, like the inert demolition waste, dust and others, no significant differences $(p>0.05)$ was found between the municipalities. The proportions of ISW are shown in Fig. 6. Other ISW waste types within the city represent $48.2 \%$, gravels and dusts $47.6 \%$ and demolition and constructions were respectively 3.4 and $0.7 \%$.

The relatively high ratio of gravel and dust waste fractions in Kamalondo and Lubumbashi is as a result of ongoing constructions works in the outskirts of the municipalities. It is crucial to mention that the township of Kampemba is essentially industrialized and mostly construction activities are ongoing in its new districts of Hewa-Bora and Bel-Air which usually undergoes transformation each year. Further, in the 22 districts of Lubumbashi city, the financing of buildings construction is completely undertaken by the householders accounting for 19 districts out of 22 thus, leaving the remaining districts impoverished socioeconomically. Practically, all recent extensions of the city of Lubumbashi are districts of auto construction (DSCRP, 1999). To enhance effective collection of ISW in this region, it is vital that inter-municipal cooperation be encouraged, which could foster improvement in administrative efficiency and create room for quality public waste management services.

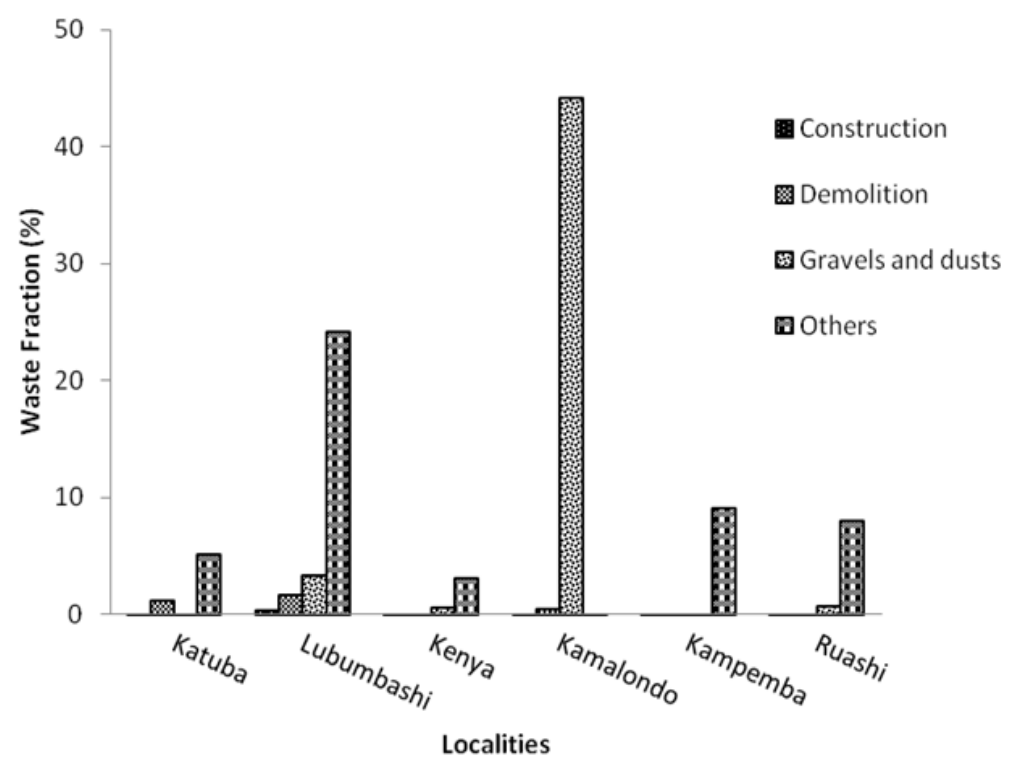

Fig. 6. Proportion of inert solid waste fractions from seven municipalities in Lubumbashi 


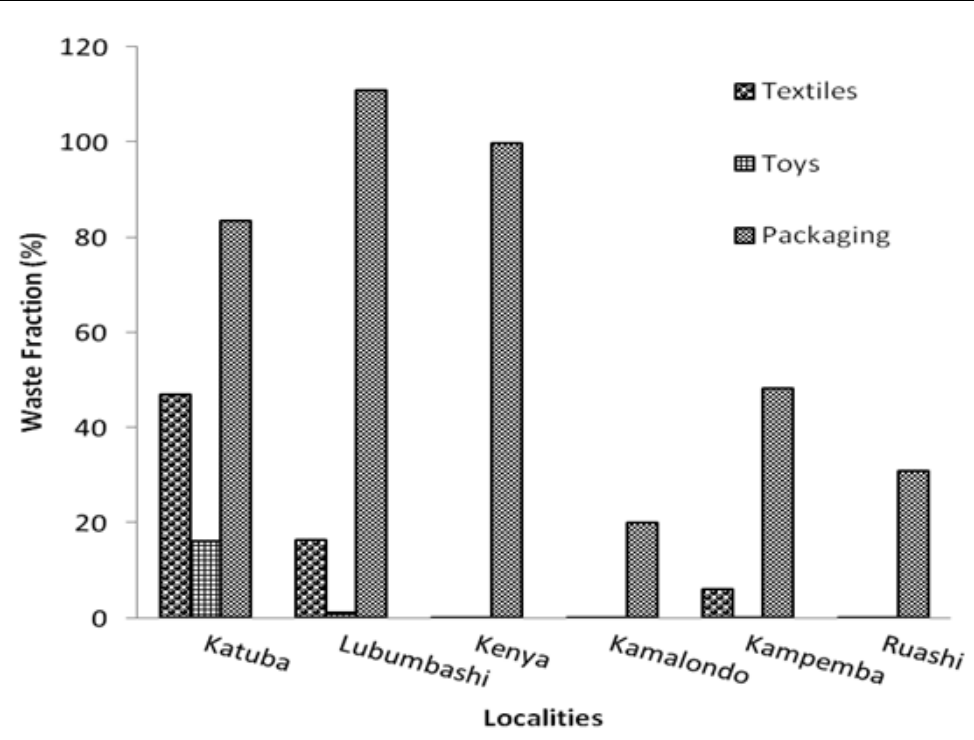

Fig. 7. Composite solid waste fractions from the city of Lubumbashi

\section{Composites Solid Waste}

The Composites Solid Waste (CSW) fractions in the various cities represent the amount of organic matter generated and disposed of in landfills. The proportion of CSW in Lubumbashi municipalities makes up 36\% of the total collected waste (Fig. 3). The highest proportion of CSW was found in Katuba, 30.4\%, followed by Lubumbashi, 26.7\%, Kenya, 20.8\%, Kampemba and Ruashi, 11.3 and $6.6 \%$ respectively. Kamalondo had the least CSW fraction, $4.2 \%$. The Composites Solid Waste (CSW) fraction is shown in the Fig. 7. CSW identified include packaging, toys and textile waste. Packaging waste dominates with $81.6 \%$ followed by textiles waste with $14.7 \%$. Tracing packaging waste, Lubumbashi dominates with $110.9 \%$ followed by Kenya with $99.8 \%$ and Katuba, $83.5 \%$. In the textile waste category, Katuba dominates with $42 \%$ followed by Lubumbashi with $16.5 \%$ and Kampemba with 6\%. Moreover, variance analysis reveal no significant difference $(p>0.023)$, comparing the percentage of textile waste. Thus, the people of Katuba use far more textile materials unlike Lubumbashi, Kampemba, Kenya, Ruashi and Kamalondo.

The presence of copious commercial activities in the township of Lubumbashi made it a stronghold for host of packaging waste. However, the relatively high amount of packaging waste in Kenya municipality is owing to the industrial settings of the area. Essentially, all households in Lubumbashi districts occupy a parcel of land. Unlike Lubumbashi, the municipalities of Kampemba, Katuba, Kenya and Rwashi are known for their extreme population growth compared to available infrastructure and facilities. Hence, the high proportion of CSW generated in these zones especially in Katuba. DSCRP
(1999), revealed that about $66.7 \%$ of the households in this municipality are from modern city (down town inherited from colonization) whose administrative settings originates from the General de Carrières de Mines (GECAMINES) company. The area is occupied by offices, shops, large markets, super markets and several business stores, which explains the reason why the proportion of CSW was higher than other municipalities. Based on this setting, it will be highly important for authorities to install a central waste collection system targeted especially on this class of waste, which invariably could aid better sorting and recycling activities.

\section{Hazardous Solid Waste (HSW)}

The Hazardous Solid Waste (HSW) fractions in the various cities represent the amount of organic matter generated and disposed of in landfills. The proportion of HSW in Lubumbashi municipalities make up 3\% of the total collected waste (Fig. 3). Within the municipalities, varying quantities of HSW were observed in Lubumbashi ( $8 \%$ of Total Municipality Waste (TMW)) and Katuba (3\% TMW) municipalities, respectively. The proportion of hazardous solid waste is shown in the Fig. 8. The medical waste dominates with $63.2 \%$, followed by lamps waste, $8.4 \%$, insecticides waste $7.9 \%$, devices and oils are respectively 5.8 and $5.7 \%$. Variance analysis showed that the percentages of waste paint are significantly different $(p=0.05)$ when comparing the HSW in all municipalities. The remaining waste fractions showed a similar trend $(p>0.05)$. Thus, the municipality of Kamalondo with $0.4 \%$ produces much waste paint compared to other municipalities (except Lubumbashi), which comes from maintenance of business houses. 


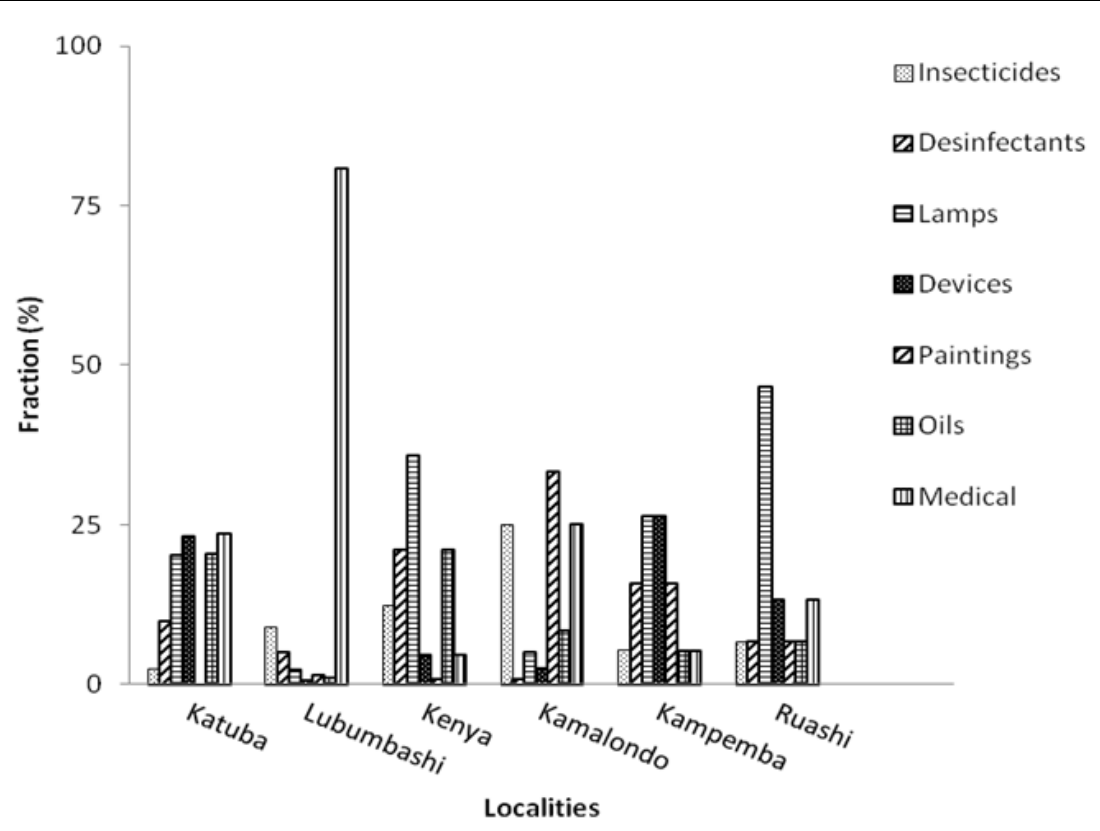

Fig. 8. Fractions of hazardous solid waste from municipalities in Lubumbashi city

As seen from Fig. 8, medical waste could be found nearly in all the municipalities. The prevalence of this class of waste in the township of Lubumbashi is justified by the presence of huge medical structures at the level of provincial authority, representing the medical structures of the state and private medical structures. For example, the academic clinics, Sendwe and Gécamines hospitals, are among the government and private medical structures existing in Lubumbashi municipality. One of the major setbacks resulting in the profuse generation of this class of waste is the limited knowledge on technologies and good practices for waste management and lack of proper planning and efficient decision making on environmental issues. To tackle this menace, awareness campaigns can be used to influence the behavior of individuals and stakeholders towards adopting an efficient HSW management practices.

\section{Technical Approaches to Waste Management in Lubumbashi}

Collection of waste includes temporary storage or containerization, transfer to collection vehicle and transport to a site where the waste undergoes processing and ultimate disposal. Processing and final disposal are challenging problems, but waste collection is the most expensive phase, largely because it is labor intensive. Proper waste collection techniques are therefore important to protect public health, safety and environmental quality.

The Environmental Protection Agency (EPA) has developed recommended procedures for the collection and storage of solid waste; these activities must be conducted in a way that will not compromise health, safety or provide food and shelter for disease vectors (for example, rats and flies). Enforcement of these regulations is solely assign to the states and local communities. Proper on-site storage is of particular importance for municipal waste containing a significant amount of putrescible garbage. Water tight, rust-resistant containers with suitable covers reduce the incidence of rodent or insect infestation and offensive odors and unsightly conditions may be kept at a minimum, if the containers and storage areas are washed periodically. The EPA recommended that waste be collected at least once a week and trashes at most once every 3 months (Table 2).

Sustainable Municipal Solid Waste Management (MSWM) has been accepted and practiced by city managers for some time now. However, with different social and economic realities, consumption patterns and technological development levels, municipalities in different countries have adopted varying approaches to sustainably manage waste generation (Chen et al., 2010). Similar findings were made by Erses Yay (2015), who demonstrated that an integrated system of composting, MRF (materials recycling facility), incineration and landfilling is considered a solution towards improved sustainability and thereby overcoming the prevailing waste management problem. Their founding also showed that life cycle assessment could be a valuable tool for environmental managers in planning an integrated waste management scheme for a more tenable environmental platform.

Incineration is a tried and tested technique in many developed countries and developing countries, even 
though this technique is controversial for many reasons. The controversy generally concerns environmental and sanitary issues connected to incinerators that have operated in the past before the application of present principle guiding waste incineration. Other approach suggested in this study is sorting and separation of waste at the household level.

\section{Conceptual Model for Solid Waste Management in Lubumbashi}

\section{Theoretical Framework}

A Municipal Solid Waste Management (MSWM) model is one that integrates multifaceted techniques of waste management to essentially facilitate the efficiency of MSWM in developing country. The model developed in this study highlights the importance of some three dimensions employed in the evaluation and evolution of an efficient solid waste management system for developing localities like Lubumbashi city. These include: (a) Interest of participants in solid waste management-From the generation points to treatment and final disposal, the elemental stages of the movement or flow of materials and the characteristics through which the system is analyzed involves households, services users, NGOs, informal, formal private sector, municipality, ministry and others (Guerrero et al., 2013); (b) residential approach, which involves separation of different solid waste types using three kinds of bin bag (one for biodegradable, hazardous solid waste and recyclable solid waste) to aid waste collection. Typically, municipal staff visually inspects the city neighborhoods randomly and check for cleanliness or react to complaints by residents; (c) is the private sector. There are evidence from interviews conducted that private companies play effective roles in solid waste collection and are able to do so at a lower service cost (Lohri et al., 2014; Oteng-Ababio et al., 2013).

This present work is set within an adapted MSWM framework as described in Fig. 9. Principally, the model sets out to investigate the participants' action, comportment and issues that influence the elements of the municipality's waste management system, the technical approaches, environmental, socio-cultural, legal, institutional, economic and environmental education and bonds present to enable the overall system functioning. This framework is constructed according to the local urban decree (BureauDuMaire, 2001). This decree basically has five articles. The first three sections briefly describe how to proceed, clearly indicating the appropriate places to deposit the garbage. The last two illustrate the sanctions provided in case of violation of the decree and the authorities responsible for overseeing the execution of the decree. In 2007, another decree was enacted, in this case, an urban decree (BureauDuMaire, 2005), concerning the rejection of packaging containers, cans and other waste found on the road or public places of Lubumbashi city.

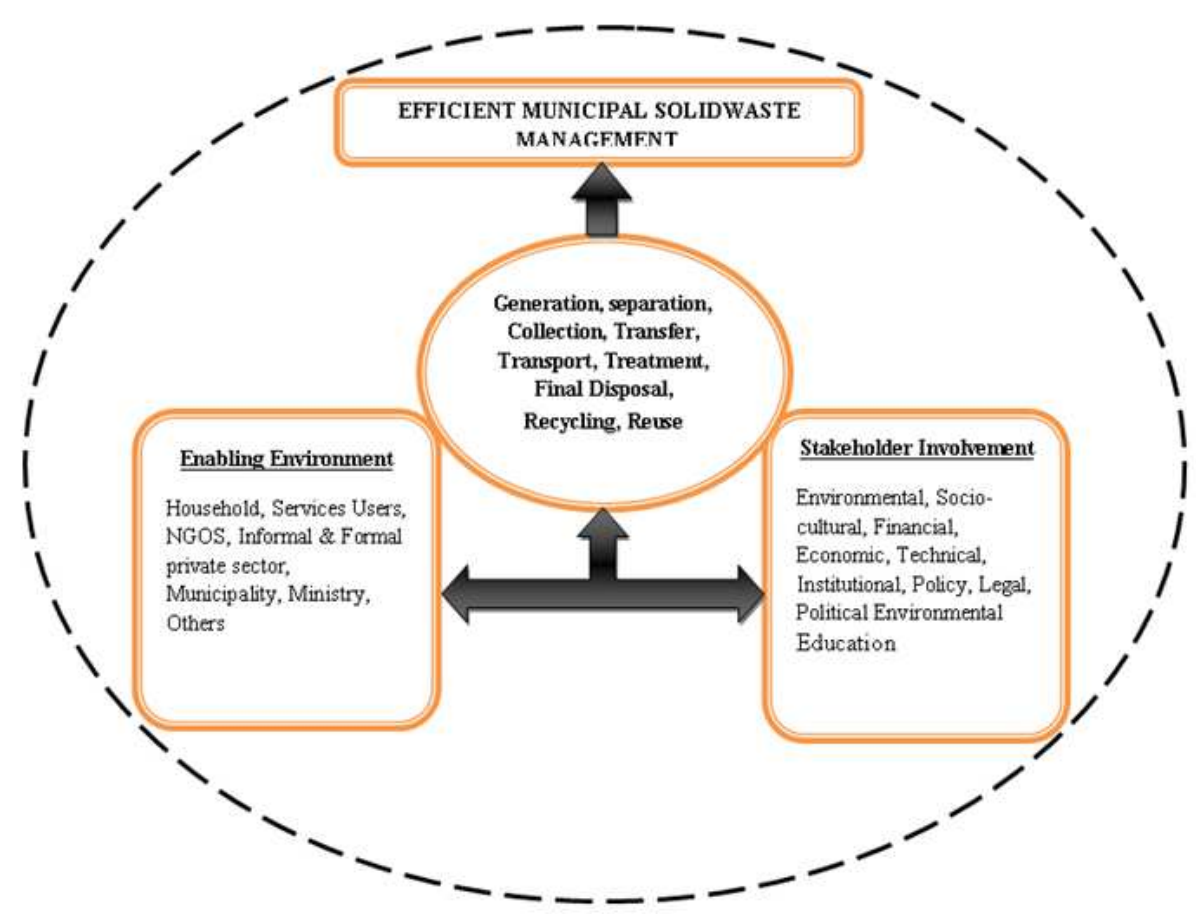

Fig. 9. Conceptual model for efficient management of municipal solid waste in Lubumbashi 
To implement the model, existing elements of the waste management systems are defined in terms of waste generation and separation, collection, transfer and transport, treatment, reuse, recycling and final disposal. The first stage is set as; collection and separation of solid waste using different bin bags as suggested earlier in this section. Second stage will involve transport of solid waste to three locations for recycling, reuse or landfilling. Recycling involves transformation into others essentials objects. Reuse implies the re-utilization of (e.g., papers; plastics for artistic carving locally; rubber tire to lock up houses, build chairs and so on; scoria, obtained after melting of copper, cobalt, iron, zinc for building pavements; and agricultural remains for composting) used materials. Landfilling options that can be suitably applied include; sanitary landfill and the synergistic production of gas as additional energy source for electricity shortage.

\section{Conclusion}

Lubumbashi produces well above the $1 \mathrm{~kg}$ per day per person bench mark of solid waste generation but only 264 tons of solid waste per day or 95,040 tons per year were retrievable from available collection systems that are still operational. Each waste categories identified in this study seems to be more dominant in certain municipality than others depending on the prevailing socio-economic activities of the area. As seen from the study, Lubumbashi and Kampemba generates more waste from construction works than other municipalities. This trend is elucidated by the ongoing construction activities in the outskirts of the municipality of Kampemba. Similarly, Kamalondo produces much waste paint which originates from maintenance of business houses.

Factors including population explosion, urban activities, poverty and weakness of public power aided the proliferation of solid waste (domestic, industrial, manufacturing, medical, agricultural, sewage sludge and so on) in Lubumbashi. Lack of environmental education, green spaces, sidewalks, rails, culverts and good roads were identified setbacks limiting MSWM in Lubumbashi city. Urgent reforms are required to: (a) Mobilize more domestic resources; (b) improve public resource management and build administrative capacity; (c) build capacity in terms of service provisions and management of national institutions with directed focus on major infrastructural sectors, particularly with a view to improving the population's quality of life and promoting increased private investment in the productive sectors of the economy; and (d) strengthen internal and external audit structures as well as those involved in combating corruption, like Chef Strategy Officers (CSOs) able to promote overall demand of good governance.

\section{Acknowledgement}

The authors are grateful to Observatoire Congolais de l'Environnement (OCE), Action pour l'environnement, l'Urbanisme et le Développement Durable (EAUD), Non Governmental Organizations (NGOs), University of Lubumbashi (UNILU) and all the staffs of the Environmental Quality Research, DR. Congo, for their materials support. This work was financially supported by OCE and EAUD.

\section{Author's Contributions}

All authors made valuable contribution during the formulation of the research, development and publication of the manuscript.

\section{Ethics}

This article is original and contains unpublished material. We confirm that all authors have read and approved the manuscript and there are no conflicts of interest.

\section{References}

Arkamose, A.A., 2004. L'état de l'environnement en République Démocratique du Congo à l'aube du IIIème millénaire. Theme IV. Degradation des sites urbains par erosion et inondations.

Bernad-Beltran, D., A. Simo and M.D. Bovea, 2014. Attitude towards the incorporation of the selective collection of biowaste in a municipal solid waste management system. A case study. Waste Manage., 34: 2434-2444. DOI: 10.1016/j.wasman.2014.08.023

Brinkhoff, H.C., 2010. Population statistics for countries, Administrative areas, Cities and AgglomerationsInteractive Maps and Charts.

BureauDuMaire, 2001. Arrêté urbain nº0/burmaire/ville/l'shi/2001 du 23/11/2001 rendant obligatoire l'usage de la poubelle dans la ville de lubumbashi.

BureauDuMaire, 2005. Arrêté urbain $n^{\circ} 003 /$ burmaire/ville/l'shi/2005 du 27/01/2005 portant interdiction de stocker ou d'entreposer les hétérogenités dans les parcelles résidentielles.

Chen, X., Y. Geng and T. Fujita, 2010. An overview of municipal solid waste management in China. Waste Manage., 30: 716-724.

DOI: 10.1016/j.wasman.2009.10.011

Cimpan, C., M. Rothmann, L. Hamelin and H. Wenzel, 2015. Towards increased recycling of household waste: Documenting cascading effects and material efficiency of commingled recyclables and biowaste collection. J. Environ. Manage., 157: 69-83.

DOI: 10.1016/j.jenvman.2015.04.008 
Cobbinah, P.B., M.O. Erdiaw-Kwasie and P. Amoateng, 2015. Africa's urbanisation: Implications for sustainable development. Cities, 47: 62-72. DOI: $10.1016 /$ j.cities.2015.03.013

DSCRP, 1999. Développement urbain dans la province de katanga. Document des stratégies de réduction de la pauvreté.

Erses Yay, A.S., 2015. Application of Life Cycle Assessment (LCA) for municipal solid waste management: A case study of Sakarya. J. Cleaner Product., 94: 284-293.

DOI: $10.1016 / \mathrm{j}$.jclepro.2015.01.089

Garcia, A.J., M.B. Esteban, M.C. Marquez and P. Ramos, 2005. Biodegradable municipal solid waste: Characterization and potential use as animal feedstuffs. Waste Manage., 25: 780-787. DOI: 10.1016/j.wasman.2005.01.006

Guerrero, L.A., G. Maas and W. Hogland, 2013. Solid waste management challenges for cities in developing countries. Waste Manage., 33: 220-232. DOI: 10.1016/j.wasman.2012.09.008

Henry, R.K., Z. Yongsheng and D. Jun, 2006. Municipal solid waste management challenges in developing countries--Kenyan case study. Waste Manage., 26: 92-100. DOI: 10.1016/j.wasman.2005.03.007

Kassim, S.M. and M. Ali, 2006. Solid waste collection by the private sector: Households' perspectiveFindings from a study in Dar es Salaam city, Tanzania. Habitat Int., 30: 769-780. DOI: $10.1016 /$ j.habitatint.2005.09.003

Kottek, M., J. Grieser, C. Beck, B. Rudolf and F. Rubel, 2006. World Map of the Köppen-Geiger climate classification updated. Meteorologische Zeitschrift, 15: 259-263.

DOI: $10.1127 / 0941-2948 / 2006 / 0130$
Kubanza, N.S. and D. Simatele, 2015. Social and environmental injustices in solid waste management in sub-Saharan Africa: A study of Kinshasa, the Democratic Republic of Congo. Local Environ. DOI: $10.1080 / 13549839.2015 .1038985$

Lohri, C.R., E.J. Camenzind and C. Zurbrugg, 2014. Financial sustainability in municipal solid waste management--costs and revenues in Bahir Dar, Ethiopia. Waste Manage., 34: 542-552. DOI: $10.1016 /$ j.wasman.2013.10.014

Memon, M.A., 2010. Integrated solid waste management based on the 3R approach. J. Mater. Cycles Waste Manage., 12: 30-40. DOI: 10.1007/s10163-009-0274-0

Nsokimieno Eric, M.M., E. Bailey, M.T. Martin, C. Abraham and J. Li et al., 2014. Ongoing informal settlements in democratic republic of Congo: Implementing new urban policy for creating sustainable neighborhoods. J. Sustainable Dev., 7: 254-256. DOI: 10.5539/jsd.v7n5p254

Oteng-Ababio, M., J.E. Melara Arguello and O. Gabbay, 2013. Solid waste management in African cities: Sorting the facts from the fads in Accra, Ghana. Habitat Int., 39: 96-104.

DOI: 10.1016/j.habitatint.2012.10.010

Owusu Boadi, K. and M. Kuitunen, 2002. Urban waste pollution in the Korle Lagoon, Accra, Ghana. Environmentalist, 22: 301-309. DOI: $10.1023 / \mathrm{a}: 1020706728569$

Patel, Z., 2009. Environmental justice in South Africa: Tools and trade-offs. Soc. Dynam., 35: 94-110. DOI: $10.1080 / 02533950802666956$

Põldnurk, J., 2015. Optimisation of the economic, environmental and administrative efficiency of the municipal waste management model in rural areas. Resources Conser. Recycl., 97: 55-65. DOI: $10.1016 /$ j.resconrec.2015.02.003 